\title{
18 THE PROBLEMS OF FEMALE GENITAL MUTILATION FOR MUSLIM AND EJAGHAM WOMEN OF CAMEROON
}

\section{Helen Namondo Linonge-Fontebo ${ }^{1}$}

\section{INTRODUCTION}

Female genital mutilation (FGM), also known as female circumcision, is an ancient traditional ritual practised in Asia, Africa and by Aboriginal Australians. ${ }^{2}$ On the African continent, the highest rates of FGM are found amongst the sub-Saharan countries located in the Horn of Africa (Sudan, Somalia, Eritrea, Ethiopia and Djibouti). ${ }^{3}$ Currently, it is practised in at least 28 African countries in the sub-Saharan and North African regions, in the Arab countries of Oman, South Yemen, Egypt, the United Arab Emirates and amongst the Muslim populations of Indonesia and Malaysia. ${ }^{4}$ Amongst married Egyptian women, 97 percent between the ages of 15 and 49 have undergone the procedure. In the African country of Tanzania, FGM affects about 18 percent of the female population and mass circumcisions are carried out in which thousands of girls are genitally mutilated. In one such ceremony, after 5,000 girls were subjected to FGM, twenty died from medical complications. ${ }^{5}$

Prior to the 1990s, the World Health Organization (WHO) did not take appropriate measures to combat FGM, because it was considered an African problem, but today FGM is a global concern. Migration from Africa and practising countries has caused the United States, Europe and Australia to be confronted with FGM. Therefore, FGM is not unique to Cameroon or Africa, but it is also a concern from North America to Europe, Asia and Oceania. ${ }^{6}$

1 Senior Lecturer, Department of Women and Gender Studies and Secretary General, Faculty of Social and Management Sciences, University of Buea.

2 Abdallah R. 1982. Sisters in affliction: Circumcision and infibulation in women in Africa. London: Zed Books.

3 Ahmadi ABA. 2013. "An analytical approach to female genital mutilation in West Africa", International Journal of Women's Research 3(1):37-56.

4 Center for Reproductive Rights. 2006. Female genital mutilation: A matter of Human Rights, An advocate's guide to action. New York: Center for Reproductive Rights.

5 Lips HM. 2003. A new psychology of women: Gender, culture and ethnicity. Second Edition. New York: McGraw-Hill, 6.

6 Wahedi S. 2018. "Female circumcision as an African problem: Double standard or harsh reality", in Green MC, Gunn TJ and Hill M (eds). Religion, Law and Security in Africa. Stellenbosch: AFRICAN SUN MeDIA, 385-402. 
The term "female genital mutilation" came into existence after the 1990 Inter-African Committee Conference on Traditional Practices against women. ${ }^{7}$ According to the World Health Organization (WHO) ${ }^{8}$ and UNICEF, ${ }^{9}$ FGM is defined as "comprising all procedures that involves partial or total removal of the external female genitalia, or another injury to the female genital organs for non-medical reasons". The day of 6 February was earmarked by the United Nations as the International Day of Zero Tolerance for FGM. More than 200 million girls and women in at least 30 countries in the world, precisely in most parts of Africa, Cameroon-inclusive, and to a lesser extent some regions of the Middle East, have undergone FGM.${ }^{10}$ Furthermore, it is estimated that three million girls are at risk of female circumcision annually, and in most practising countries girls have been circumcised before the age of five. ${ }^{11}$

The FGM prevalence rate in Cameroon is 1.4 percent. ${ }^{12}$ Even though national rate is low, there are regions with high rates. In the Extreme North region of Cameroon, the prevalence rate is 13 percent for the Fulbe people and people of Arab descent. The prevalence varies with religion: FGM is prevalent in 6 percent of Muslim women, less than 1 percent of Christians. This low overall prevalence conceals wide regional disparities, especially in Manyu in the South-West and Logone, and Chari in the Extreme North of the country. Amongst the communities affected, religious denomination plays a role in determining whether or not a woman is subjected to the practice. All Muslim women, and two thirds of Christian women, are victims of the practice.

The Ejaghams, called the "Ekoi", and the Muslims living in Ejagham villages are located in the Eyumojock Sub-division in Manyu in the South West Region of Cameroon. The Ekoi are said to be closely related to the people of the south eastern region of Nigeria, that is, the Efik, Ibibio and the Annang. ${ }^{13}$ Socio-politically, the Ejagham ethnic group have diverse languages, including Keyaka, Ngounaya, Ejagham and Njemaya. While the women are often initiated into the nkim clubs organised around the moninkim, or circumcision dance ceremony, and the men are

7 Shell-Duncan B. 2001. “The medicalization of female 'Circumcision': harm reduction or promotion of dangerous practice?", Social Science \& Medicine 52(7):1013-1028.

8 World Health Organization (WHO). 2018. "Female Genital mutilation: Fact Sheet", 31 January.

9 UNICEF. 2016. “New statistical report on female genital mutilation shows harmful practice is a global concern - UNICEF", 5 February.

10 WHO, "Female Genital Mutilation: Fact Sheet"; UNICEF, "New statistical report on female genital mutilation".

11 World Health Organization (WHO). 2016. WHO guidelines on the management of health implications from female genital mutilation. Geneva: WHO Press.

12 WHO, "Female Genital Mutilation: Fact Sheet"; UNICEF, "New statistical report on female genital mutilation".

13 Eberhard DM, Simons GF and Fennig CD (eds). 2019. "Cameroon”, Ethnologue: Languages of the World. Twenty-second Edition. Dallas, TX: SIL International. Online at: http://www. ethnologue.com 
often initiated into the secret cults called angbu for young boys and the ngbe and ekpe groups, which are the leopard societies for adult men who often perform during funeral rites. The religious affiliation of the Ejaghams is closely tied to a cultural myth that there is life after death, because they have two deities, the Obasi Osor (God of the sky) and Obasi Nsi (God of the ground), who are believed to have the powers to make the decay body of a dead man to rise to the God of the sky. ${ }^{14}$ The powers of these deities are likened to the powers of the God of Christianity during the resurrection of Jesus Christ.

The Ejagham villages in the Eyumojock Sub-division of the South West Region of Cameroon along the Mamfe-Nigeria road and the Muslims in the three northern regions of Cameroon dominate in the practice of FGM. The practice has been identified by the Convention on the Elimination of all Forms of Discrimination Against Women (CEDAW) and other international human rights documents ratified in Cameroon as "violence against women", and it violates the fundamental human rights of women and girls to be protected from harmful traditional practices. In spite of the awareness of families of the serious health consequences of FGM, the act is usually done without the consent of the girls, thereby depriving them of the opportunity to make independent decisions about their bodies and sexual health.

Against this religious and cultural backdrop, research has proven that regardless of the efforts put in place by human rights activists, NGOs, policy makers, medical institutions and scholars to respond to the practice of FGM through legal awareness and sensitisation through educational programmes, necessitating that the culture of the people be revisited if success rates are to be attained. This explains why a Cameroonian local anti-female circumcision activist, Vitalis Ngambouk ${ }^{15}$ argues that some studies have produced mixed outcomes in the case of the Ejaghams and the Muslims in Cameroon, where national activists have failed to recognise the socio-political and cultural history of these people in interventions aimed at bringing an end to FGM and protecting the girl child from harmful traditional practices. In this light, this chapter therefore addresses the following questions: What are the perceptions of FGM within the Ejagham and Muslim community? Or, why practise FGM? What are the short-term and long-term effects of FGM on the health of women and girls? What initiatives have been put in place by the local community to terminate this practice? What has the government been doing to eradicate female genital mutilation?

The study underlying this chapter is based on a mixed method approach, using content analysis as a point of departure. The researcher interviewed 108 respondents, all from the Ejagham villages, as well as some Muslim imams based in the

14 Bayen BP. 2016. The effects of female genital mutilation in Cameroon: Case study Ejagham community of Eyumojock sub-division, MA Thesis, Linnaeus University.

15 Ngambouk VP. 2010. “Gendered identity and anti-female genital cutting (FGC) activism among the Ejaghams", Arts $\mathcal{E}$ Sciences Journal Cameroon. Online at: http://astonjournals. com/manuscripts/Vol2010/ASSJ-15_Vol2010.pdf 
English-speaking South West Region, due to the socio-political conditions prevalent in the Northern part of Cameroon, predominantly French speaking, plagued by the Boko Haram insurgency, which impeded research in that region. It is important to note that the socio-political situation prevalent in the North is even worse currently in Manyu Division from which the Ejaghams come. However, this data was carried out in February 2018, when the socio-political situation of the villages had not deteriorated to what has been prevalent since. This chapter thus focuses more on research of secondary source data for the Muslim parts of Cameroon, while both primary and secondary source data was utilised for the Ejaghams. Access into the Ejagham villages was through the traditional rulers, and informants participated in the study of free will and without coercion after being informed of the purpose of the inquiry. The informants were also informed that they could withdraw at any time they felt uncomfortable, given the sensitive nature of the study. This also explains why confidentiality and anonymity was also guaranteed to informants, given that Ejagham is a practising, traditional and conservative community with strong ties to traditional values. As such, the researcher acted in the best interest of the respondents.

\section{FEMALE GENITAL MUTILATION: AN HISTORICAL OVERVIEW}

During the nineteenth century, clitoridectomy was endorsed by physicians in Britain and the United States as treatment for "hysteria, epilepsy, melancholy, lesbianism and excessive masturbation". The "light version" of FGM was prescribed for treatment for "female masturbation and sexuality". ${ }^{16}$ It was popularised by a British gynaecologist, Isaac Baker Brown, who theorised that most diseases experienced by women could be attributed to overexcitement of the pubic nerve leading into the clitoris. Baker argued that habitual stimulation of this nerve through masturbation put enormous stress on a woman's health and would cause eight stages of progressive disease: hysteria, spinal irritation, hysterical epilepsy, cataleptic fits, epileptic fits, idiocy, mania and eventual death. ${ }^{17}$ His cure was drastic, involving "complete excision of the clitoris with scissors, packing the wound with lint, administering opium via the rectum, and strictly observing the patient" ${ }^{18}$ According to Baker, within a month, the wound usually healed, women became happy wives, rebellious teenage girls settled back into the bosom of their families and married women who were formerly averse to sexual duties became pregnant. However, this was clearly a way to control unruly girls and women. Clitoridectomy is no longer justified by medical practitioners as a way to dampen

16 Lavazzo C, Sardi T and Gkegkes L. 2013. Female Genital Mutilations and infections: $a$ systematic review of the clinical evidence. Springer-Verlag: Berlin.

17 Lips, "New psychology of women”.

18 Lavazzo C et al., Female Genital Mutilations and infections. 
women's sexuality; nevertheless, the operation is still frequently performed. Surgery on the clitoris is done cosmetically, to make a child "look" like a girl. Removing or reshaping of all or part of the clitoris, called clitoroplasty by modern surgeons, happens about five times a day in the United States. ${ }^{19}$

Some scholars and countries suggest medicalisation of FGM is not the case in Cameroon, where FGM is generally performed by a traditional practitioner who comes from a family in which generations of women have performed the procedure. Therefore, it is performed by untrained circumcisers or midwives, who have little knowledge of female anatomy and who travel from village to village to perform the cutting with no anaesthesia or antibiotics and absence of aseptic conditions. They use instruments such as razors, knives or scissors, which usually are reused. ${ }^{20}$ Traditional circumcisers continue to create damaging effects to the genital organs and bodies of young girls, which has required health care professionals to intervene in a bid to medicalise the practice, due to the errors committed during the circumcision process. However, WHO has strongly rejected the participation of healthcare providers in performing the same procedures under the guise of medicalisation and modernisation. ${ }^{21}$

There was no law in Cameroon prohibiting the inhuman practice of FGM until 2016, when the revised Cameroon Penal Code criminalised FGM. Despite the availability of this prohibition law, no practitioners of FGM have been prosecuted. As such, victims who do not want to undergo FGM are involved in internal migration, which greatly contributes to the spread of this practice to different parts of the country. The Demographic and Health Survey of 2004 indicated that about 1\% of the female population in Ejagham have been circumcised. The highest prevalence rates are found amongst women between the ages of 20 and 24 ( 3 percent), 5 percent prevalence for women without education, 3 percent for Muslim women and 13 percent in Ejagham (UNICEF 2004). ${ }^{22}$ Moreover, 90 percent of Manyu and the Ejagham in the South West region of Cameroon still practise FGM, supporting Sohail Wahedi's argument that in some practising countries, up to 90 percent and close to 100 percent of girls and women have been circumcised, especially amongst some tribes in Ethiopia. ${ }^{23}$

19 Lavazzo C et al., Female Genital Mutilations and infections.

20 Lavazzo C et al., Female Genital Mutilations and infections.

21 WHO, WHO guidelines on the management of health implications.

22 Institut National de la Statistique - INS/Cameroun and ORC Macro. 2005. Enquête Démographique et de Santé du Cameroun 2004 [Demographic Health Study of Cameroon, 2004]. Calverton, MD: INS/Cameroun and ORC Macro. Online at: https://dhsprogram. com/publications/publication-fr163-dhs-final-reports.cfm

23 Wahedi S. 2018. "Female circumcision as an African problem: Double standard or harsh reality" in Green MC, Gunn TJ and Hill M (eds). Religion, Law and Security in Africa. Stellenbosch: AFRICAN SUN MeDIA, 385-402. 


\section{FEMALE GENITAL MUTILATION IN INTERNATIONAL HUMAN RIGHTS LAW}

Article 1 of the Protocol of the African Charter on Human and People's Rights on the Rights of Women (Maputo Protocol) identifies violence against women as acts perpetrated against women which may potentially or actually cause physical, sexual, psychological and economic harm, a description which characterises FGM. ${ }^{24}$ Article 3 of this same Protocol highlights the right of every African woman to dignity, which is the right to the recognition and protection of her human and legal rights, and Article 5 says that every woman is entitled to respect for her life and the integrity and security of her person. This provision further prohibits cruel, inhuman and degrading treatment. FGM violates this provision in every way and is to be deplored as having far-reaching repercussions on women and young girls' bodily integrity and dignity, especially when the procedure is carried out under unsuitable and coercive circumstances. Article 12 of CEDAW provides that state parties shall take all appropriate measures to eliminate discrimination against women in the field of health care in order to ensure, on a basis of equality between men and women, access to health care services, including those related to family planning. ${ }^{25}$ The Beijing Declaration and Platform for Action call upon governments to take action against FGM. ${ }^{26}$ Article 5 of the Beijing Platform articulates that states should adopt and change all forms of culture and tradition that prejudices women, making the man superior to the woman, while Article 10 of the Beijing Platform states that women should have access to all information that will improve the quality of their well-being. The WHO has called on member states to eliminate all acts or practices that are extremely discriminatory to women and girls. ${ }^{27}$ The $\mathrm{WHO}$ requires countries to put an end to all forms of cultures and acts, which constitute discrimination against women.

The UN expects signatories of CEDAW to fight discriminatory practices like FGM; yet this is only done to a limited extent in Cameroon. Many states besides Cameroon have adopted the CEDAW articles, but they lack the political will and finances to implement and enforce these rules within the territories. According to Corinne Packer, a population health researcher, the bottleneck of enforcing the laws against FGM is the lack of political commitment by some state actors for fear

24 Protocol to the African Charter on Human and Peoples' Rights on the Rights of Women in Africa, adopted by the 2nd Ordinary Session of the Assembly of the Union, Maputo, CAB/LEG/66.6 (Sept 13, 2000); reprinted in 1 Afr. Hum. Rts. L.J. 40, entered into force Nov. 25, 2005. Online at: http://www.achpr.org/instruments/women-protocol [hereafter AU Women's Protocol].

25 Convention on the Elimination of All Forms of Discrimination against Women, G.A. res 34/180, 34 U.N. GAOR Supp. (No. 46) at 193, U.N. Doc. A/34/46, entered into force Sept 3, 1981, art 12.

26 Beijing Declaration and Platform for Action, fourth world conference on women, Beijing, China, Sept 4-15, 1995, U.N. Doc. A/CONF.177/20.

27 WHO. 1998. Female Genital Mutilation: An overview. Geneva: WHO Press, 51, art 12(f). 
of antagonising traditional elites or communities that they can lobby electorates. ${ }^{28}$ Many statesmen do not want to fight decades-old traditions for fear of not being re-elected into power. Packer further argues that the constitutional laws and penal codes in some of these states with the will power to stamp out FGM either are not powerful enough or there is a lack of will from enforcing authorities.

\section{FEMALE GENITAL MUTILATION IN CAMEROON LAW}

The U.S. Embassy in Yaoundé, Cameroon, noted in a February 2012 document on FGM that, "The practice is often performed by untrained practitioners, employing no anaesthesia and often using such instruments as broken glass, tin lids, scissors, or unsterilised razors." ${ }^{29}$ A 2012 Red Cross document noted that, "In Cameroon, FGM is carried out in a barbarous manner by traditional midwives with no medical training, without anaesthesia and using rudimentary instruments." 30 An abstract of a U.S. National Library of Medicine report on FGM in Cameroon from 1995 noted that, "Only $1.3 \%$ of procedures were performed in hospitals; the remainder were performed by traditional practitioners." 31

Section 27 of the Southern Cameroon High Court Law (SCHCL) 1955 ensures the observance of native law and custom, only on the condition that it is not repugnant to natural justice, equity and good conscience or incompatible, either directly or by implication, with any law in force in the Republic. Therefore, applying the native law and custom of FGM, which sustains discrimination based on the sex of individuals, is bad law. There is confusion emanating from the fact that the Cameroon Penal Code (CPC) of 1974, revised in 2016,32 criminalises FGM; yet the practice still persists amongst the Muslims in Northern parts of Cameroon and the Ejaghams of South West Region. The prohibition law protects physical and bodily integrity of persons, and the penal code enacted on 12 July 2016 has specific provisions on genital mutilation. Section 277(1) of the CPC prohibits genital mutilation of all persons in stating: "Whoever mutilates the genital organ of a person, by any means whatsoever, on conviction is subject to imprisonment from 10 to 20 years, and imprisonment for life if the offender habitually carries out this practice, does so for commercial purposes, or if the practice causes death."

In light of these international legal norms and national law requirements, it is incumbent on the Cameroonian government to implement the law on FGM, as

28 Packer C. 2005. "Circumcision and Human Rights Discourse", in Nnaemeka O and Ezeilo J. (eds). Engendering human rights: cultural and socio-economic realities in Africa. New York: Palgrave.

29 Ntaryike D. 2014. "Cameroon encounters resistance to female circumcision ban", VOA News, 12 June.

30 Bayen, The effects of female genital mutilation in Cameroon.

31 Bayen, The effects of female genital mutilation in Cameroon.

32 Cameroon Penal Code. Law No. 65-LF of 12 November 1965 and Law No. 67-LF-1 of 12 June 1967, revised in 2016, sec 277(1). 
stated in the CPC, given that human rights activists and gender experts view FGM as an act of violence against women that infringes upon women and girl's rights and brings damaging physical, psychological and social effects. The operation transgresses the right to health, gender identity, and the rights of girls and women to corporal integrity. It is commonly practised on girls between the ages of 4 and 10 years without their informed consent. These girls are compelled to do so by traditional cultural demands or parental authority, which is a violation of their rights to make decisions about their bodies. ${ }^{33}$ FGM therefore threatens the integrity of the body and the sexual and reproductive rights of women.

\section{REASONS FOR PRACTISING FEMALE GENITAL MUTILATION AND EFFECTS GLOBALLY AND IN CAMEROON}

There are no specific grounds justifying the practice of FGM worldwide. Although many reasons have been advanced for the practice of FGM, parents have their own reasons for circumcising their daughters, which vary amongst countries and regions. Many researchers suggest that FGM is meant to limit and control female sexuality and perpetuate the subordination of women by emphasising patriarchal values, such as femininity, chastity, the transition or rite of passage to adulthood. It is also undertaken for reasons of female hygiene, protecting girls marriageability and saving their families' honour, since non-adherence to the FGM practice stigmatises and isolates girls and their families, resulting in disapproval and loss of social status. ${ }^{34}$ The procedure is also done to enhance fertility, to please the husband, and for reasons of beauty and aesthetics, to name a few more common reasons, but all hooked under the umbrella of culture or tradition. ${ }^{35}$ For centuries, women in certain cultures have been taught that these painful and dangerous procedures are important for their health, beauty and social status.

A 28-year-old Eritrean woman had this to say: "My mother, my grandmother and my great-grandmother all told me it was right, that without it a woman wouldn't be able to control herself, that she would end up a prostitute ... I even learnt to believe that it looked nicer that way. We grew up reciting the saying, 'A house isn't beautiful without a door."' 36 Defenders of the practice argue that women who have not been subjected to FGM are oversexed and impolite and end up being bad wives.

33 World Health Organization (WHO). 2008. Eliminating female genital mutilation: an interagency statement. Geneva: WHO Press.

34 Exterkate M. 2013. Female Genital Mutilation in the Netherlands: Prevalence, incidence and determinants. Utrecht: Pharos.

35 Abd El Hadi A. 2000. "Female Genital Mutilation in Egypt" and Abusharaf RM and Halim AM. 2000. "Questioning the tradition: Female circumcision in Sudan", in Turshen M (ed). African Women's Health. Trenton: African World Press, 145-165, 124-144.

36 Lips HM. 2003. A new psychology of women. 
Many women undergo this practice to honour male relatives in many Middle Eastern and African countries, where adultery or premarital sex committed by a wife or daughter dishonours the father, brothers and sometimes the entire family. Therefore, FGM protects male relatives by "protecting" women from temptation. ${ }^{37}$ Other writers have blamed religion as the major factor behind the practice of FGM. Yet Hilary Lips, an American psychologist, suggests that the practice of FGM predates both Christianity and Islam and is not mandated in the scripture of either religion, even though many people practise it as if it was a religious requirement. ${ }^{38}$ In many Muslim communities in the Arabian Peninsula, the circumcision of women is unknown, whereas in vast areas of sub-Saharan Africa, Cameroon included, Muslims believe that it is part of their religion. ${ }^{39}$

Circumcision in society affects both boys and girls, and this has generated debates on why female circumcision has attracted wide attention and calls for its abolition, while young boys who are at risk of being circumcised for non-medical reasons are not protected against this practice. Law and religion scholar Sohail Wahedi argues that this is based on the legal distinction that allows some extant religious rituals, such as male circumcision (MC), while outlawing other rites, such as female circumcision (FC), as contrary to the norms of civilised societies, even though some FC variants are comparable to MC. Noteworthy is the fact that while the Quran does not mention MC, Judaism does. The practice of MC by Jews is a matter of both religion and culture. In Genesis 17:10, the instruction for circumcision was very specific as God said to Abraham, "This is my covenant, which ye shall keep, between me and you and the seed after thee; every man child among you shall be circumcised." 40 Circumcision may be done to men for personal and hygienic reasons, and the Christian New Testament makes it clear that circumcision of men can be practised in order to make a man acceptable to a the particular group (Luke 1:59, Acts 16:3). From a medical standpoint, it is reported that circumcision of boys reduces risk of prostate cancer or infection with the HI-virus. ${ }^{41}$ Therefore, comparing male circumcision to female circumcision is wrong, whether with respect to the organs that are cut or the reasons for the practice. MC is restricted to cutting the foreskin of the penis; whereas FC entails cutting parts or all of the clitoris, labia minora and labia majora. According to Amal El Hadi, an Egyptian feminist activist, a ritual in men comparable to infibulation would require excising the penis and the scrotum. ${ }^{42}$ FGM is practised to control women's sexuality, whereas male circumcision is practised to enhance male sexuality.

$37 \mathrm{WHO}$, "Female Genital Mutilation: Fact sheet".

$38 \mathrm{WHO}$, "Female Genital Mutilation: Fact sheets".

39

Abusharaf and Halim, "Questioning the tradition".

40 Bible, King James Version.

41 Wahedi, "Female circumcision as an African Problem".

42 Abd El Hadi, "Female Genital Mutilation in Egypt". 
FGM has serious health consequences for women and girls, which are both short and long term. The short-term effects include: urinary salts, burns, severe deformity, bleeding, shock, chronic pelvic infections, urinary retention, tetanus infections and other effects, while the long-term effects include keloid formations, infertility, sexual problems, menstrual problems, pelvic inflammation, HIV/AIDS. ${ }^{43}$ There are also psychosocial and sexual long term consequences which include fear for sexuality, post traumatic symptoms, anxiety and depression and painful sexual intercourse. ${ }^{44}$ Through social and peer pressures, however, parents are convinced that circumcision is the best for their daughters, even if they do not want it. ${ }^{45}$

\section{EFFORTS TOWARDS ERADICATING FEMALE GENITAL MUTILATION IN CAMEROON}

The government of Cameroon has been actively involved in efforts to combat FGM since the mid-1980s, and it adopted the National Action Plan (NAP) against FGM in 1999. NAP Conducted a study on FGM in the Adamawa Region to raise awareness and commissioned local committees to combat FGM in the South West Region (Manyu), the Centre (Briqueterie Neighbourhood in Yaounde) and the Extreme North (Mayo Sava, Logone and Chari). The Ministry of Social Affairs and the Ministry of Women's Empowerment and the Family (MINPROFF) established local FGM committees in areas where FGM was most prevalent, particularly in the Extreme North Region. The signing on 25 June 2013 of a collaboration platform between MINPROFF and the Council of Imams and Muslim Dignitaries of Cameroon (CIDIMUC) to combat FGM. The organisation of advocacy sessions with parliamentarians and religious and traditional leaders of the areas concerned to raise awareness amongst families and communities on FGM during commemoration on 6 February of each year of the International Day of Zero Tolerance for Female Genital Mutilation (statistics number of people affected DSPF); entering into partnerships with community radio stations to broadcast programmes on the rights of the child, combating harmful cultural practices and FGM; implementing BIAAG Programmes (Because I Am A Girl) and LWF (Learn Without Fear) for the promotion of the education of girls and combating gender-based violence in schools all have been important initiatives to combat FGM. At the level of medical, psychological and social care: Two public centres operational in Yaoundé and Douala have been set up to take care of women victims of violence and other harmful traditional practices.

The government also provides funding and other production materials to male and female excision practitioners to enable them carry out income-generating activities. This approach was adopted by the government to compensate the excision practitioners who depend on this practice as a source for livelihood.

$43 \mathrm{WHO}$, Eliminating female genital mutilation.

44 Exterkate, Female Genital Mutilation in the Netherlands.

45 UNICEF/Innocenti Research Centre. 2005. "Changing a Harmful Social Convention: Female Genital Mutilation/Cutting", Innocenti Digest 12. 
Support for the retraining of male and female excision practitioners for alternative income-generating activities has led to the symbolic handover of the knives used for excision to the imams and Muslim dignitaries, as well as the religious and traditional leaders of the South West Region of Cameroon. The committees networked with former excision practitioners and traditional and religious leaders to reduce the practice. Government ministries and civil society organisations conducted education programmes against gender-based violence, including FGM. Cameroon is signatory to most relevant international treaties and conventions on the rights of women and children. The Constitution recognises and protects "traditional values that conform to democratic principles, human rights and the law". This is evident in Section 27 of the SCHCL 1955, as noted above.

\section{FEMALE GENITAL MUTILATION AMONGST EJAGHAM WOMEN}

Data collection for the present study was conducted over a period of two months (February-March 2018) and analysed qualitatively following a purposeful sampling technique. Findings from the in-depth interview guide provide clear evidence that FGM entails harms to women's physical health throughout their life, from the moment of cutting as an infant, to sexuality and childbirth in adulthood. The research carried out amongst the Ejagham, suggests that FGM is the cradle of tradition and beliefs. Out of the 108 randomly selected Ejagham women I interviewed, 52.8 percent of the respondents were 45 years and above, while 16.7 and 30.6 percent of the respondents were between the ages 12-19 and 20 to 45 years, respectively. The results, thus, include all the age groups, including adolescents, adults and the aged.

The majority of the 108 women interviewed were not married. The interviewed group included 62 percent single women, 18.5 percent married women and 19.5 percent widows. These results give clues on how to relate the effects of FGM to marital life and attitudes of women towards marriage in Ejagham. The educational level of the women was also sampled, since education is a prerequisite for the abolition of FGM in Ejagham. Out of the 108 women sampled from the three districts of Ejagham (Obang, Central Ejagham and Ejagham Njemaya), 50 percent had never seen the four walls of primary school, 28.7 percent had primary education, 19.4 percent had secondary education and 1.9 percent had tertiary education. This suggests a correlation between lack of education and the prevalence of FGM in Ejagham.

The prevalence of FGM amongst the 108 respondents was such that 58.3 percent women were circumcised, 16.7 percent were not circumcised and there was a 25 percent non-response rate. The 25 percent non-response rate was attributed to the fact that these women were either mutilated at an early age of their childhood and were not told or were hesitant to reveal their status. This argument can be supported by the fact that when I presented this paper that is the basis for this chapter at the sixth annual conference of the African Consortium for Law and Religion Studies (ACLARS) in Abuja, Nigeria, a university lecturer who is from the Ejagham ethnic group in Nigeria (the Ejaghams are present in both Nigeria and 
Cameroon, especially along the border between the two nations) contributed to the discussion by revealing that she was a victim of FGM and that this was conducted on her when she was still an infant. She grew up not knowing that she was circumcised until she got married, when she realised that there was such a thing as orgasm, but that she had never experienced it in her marriage. It was after investigation with her parents that she understood why she could not enjoy sex. However, she revealed that the practice of FGM has been eradicated amongst the Ejaghams in Nigeria through religious sensitisation and recommended that the same procedure be adopted for Cameroon.

Statistics from data collected reveal that amongst 108 women randomly selected in Ejagham, 89 percent are believed to have undergone circumcision, and this is done locally with the use of unsterilised tools. This implies that the prevalence of FGM within the Ejagham tribe is significantly high. Despite all efforts to clamp down on FGM in Cameroon through media sensitisation, campaigns, text books, the practice still persists, given that majority of women are still experiencing FGM today. Of the 108 women sampled, 66.8 percent attested to this fact, as opposed to 3.7 percent who never experienced it, including a 28.7 non-response rate. Out of the 108 women sampled, 49.1 percent of the women witnessed the practice less than 5 years ago, contrary to 39.8 and 11.1 percent who witnessed the practice between 6 and 10 years ago. This implies that an inverse relationship exists between media sensitisation and FGM in Ejagham.

Field data revealed that the lack of sources of information such as radio, television, libraries and newspapers on FGM contributed negatively to the sensitisation and eradication of FGM and to the root causes of the consistency of the practice. In terms of access to sources of information, 73.1 percent of Ejagham women had limited access to sources of information, while only 26.9 percent had access, making it difficult for FGM to be eradicated. When the Ejagham women were asked how they felt after being circumcised, 71.4 percent out of 108 women were not happy with the practice of FGM, because FGM is painful and there is much loss of blood. Still, 28.6 percent were happy that they had been circumcised, and this was evident in that they had expressed happiness in performing the fanciful moninkim dance, a dance reserved for those who have been circumcised. Of the 63 women who had undergone circumcision, vagina complication was the most noticeable effect. Other complications were experienced by the 26.6 percent and 17.5 percent women who had difficulties during delivery and experience low orgasm during sexual intercourse. Thus, besides the usual pains suffered by women during the process of genital cutting, there are also enormous long-term effects.

The number of children respondents had born was also taken into consideration to establish their reactions towards FGM. All of the women circumcised had female children, with 49 percent, 43.5 percent and 7.4 percent having less than three, four and five female children, respectively. This information tallies with the fact that 62 percent women circumcised also circumcised their female children and 38 percent refused to circumcise their female children. This suggests that in every 108 women 
sampled in Ejagham, only 38 percent oppose circumcising their children, against the 62 percent who practise circumcision. Among the 62 percent of respondents who circumcised their female children, 49.3 percent did so for reasons of traditional continuity, 31.3 percent for fidelity to family or group and 19.4 percent for hygiene. This indicates that those who have been circumcised do not want this tradition to die, rather they want it to continue so that every female child in Ejagham will be circumcised as they have done. Such women are not likely to agree to abandon FGM in a hurry, but rather pray for its continuity from generation to generation. This stance is also corroborated by those who opted for the eradication of FGM, as against those who opted for its continuity. The study results thus imply that some women do not find anything wrong with FGM.

Even so, the government of Cameroon is doing everything to eradicate FGM through sensitising traditional and religious leaders, as well as women and the youths, to see the practice as a human rights violation with health implications. Efforts put in place to eradicate FGM are yielding fruit, because a medical practitioner reported in an interview that:

The youths of Ejagham today say no to FGM and it should be abolished. ... youths in Manyu Division, South West Region of Cameroon are leaving the place. As a medical doctor I work with a nurse, Grace Ngwai Agbor, who today is keeping a safe distance because every now and again, she is confronted by her family members and dutifully reminded of how she must undergo the process of FGM before she will be recognised and accepted as belonging to the family. Being of the medical field herself, she has vowed that she would rather stay away from family and keep her clitoris instead of the other way around. ${ }^{46}$

The practice can only be abolished if women and traditional authorities cooperate with the government.

The findings from the study discussed above were structured and categorised into sub-themes that helped to answer questions about the problems of FGM on the Ejagham people of Cameroon. Interviews from fieldwork were used specifically to understand the current reality of the problems of FGM and why the practice still persists despite efforts to curb it. What is most significant is that the findings above reveal that, while 38 percent of Ejagham women advocate for the eradication of FGM, 62 percent still constitute a majority in support of the continuity of the practice influenced by the custom/culture of the people. The overwhelming majority supporting FGM does so contrary to international, national laws and sensitisation enforced to minimise the practice. This explains the ongoing need for recommendations and policies to be implemented by policy makers in order to achieve a 100 percent success rate at FGM eradication.

46 Home Office. 2017. "Country policy and information note". Cameroon: FGM. Online at: https//www.justice.gov/eoir/page/file/951311/download 


\section{CONCLUSION}

FGM constitutes a major public health problem affecting the health of women and girls in Cameroon. As such, the New Gender Policy Document (NGPD) in Cameroon must address it rather than just stating it as a socio-cultural practice. This document does not have a policy for FGM as other countries do. The document simply describes FGM as gender-based violence and a human right violation and ends there. Medicalisation has been adopted as an option in some countries in the hope that it will reduce the risk of complications. Unfortunately, some providers may develop a professional and financial interest in continuing the practice. Concerted efforts need to be exerted by the community, policy makers, healthcare professionals and others to eliminate this tragic practice. The Medical Association within Cameroon in collaboration with the Ministry of Public Health should review the guidelines of CEDAW regulations and the Universal Declaration of Human Rights to prohibit FGM and to provide guidance on how to treat girls and women already affected by FGM. Health professionals, and especially those involved in obstetrics and gynaecology, should be trained in the types of treatment most appropriate for FGM cases.

Statistics should be collected on women who have undergone FGM and presented themselves for medical services in hospitals. Primary care, as well as reproductive and sexual health services, should be targeted for data collection on women and children. Many former practitioners of FGM should be given formal training to understand the effects of the medical damages FGM causes on young girls. Information about new FGM cases should be reported immediately to the police and or other NGOs (partners on the field) for coordinated action to be taken so as to curb FGM. Studies about FGM should be compulsory for medical practitioners. The procedure should be documented and scholars should write about its clinical complications in medical journals. A combined legal and medical strategy, informed with knowledge of the religious and cultural support that still constitutes and obstacle to the full eradication of FGM, will be essential. 